\title{
Gender Differences in Thrombogenic Profile Associated to Coronary Obstruction Angiographically Evaluated
}

\author{
M. Vacas ${ }^{*}, 1$, Y. Sáez ${ }^{1}$, J.D. Sagastagoitia ${ }^{2}$, J.P. Sáez de Lafuente ${ }^{3}$, M. Santos ${ }^{1}$, M. Lafita ${ }^{1}$, E. Molinero ${ }^{2}$ \\ and J.A. Iriarte ${ }^{1}$ \\ ${ }^{I}$ Fundación para la Investigación y Docencia de las Enfermedades, Cardiovasculares-FIDEC, Bilbao, Spain \\ ${ }^{2}$ Servicio Cardiología-Hospital de Basurto/Departamento de Medicina, Universidad del País Vasco UPV/EHU, Bilbao, \\ Spain \\ ${ }^{3}$ Escuela Universitaria de Enfermería, Universidad del País Vasco UPV/EHU, Bilbao, Spain
}

\begin{abstract}
Objective: To identify potential differences between concentrations of thrombogenic markers associated to coronary obstruction in men and women.

Patients and Methods: We included 502 consecutive patients (251 men and 251 women), with a mean age of 63.94(11.26) and 66.08(10.58) years respectively. In all patients coronary arteriography was performed, either by presenting an acute coronary episode or for discard coronary heart disease (CHD). CHD was defined as a $\geq 50 \%$ narrowing of lumen in one of the three major coronary arteries. At the hospital admission, a blood sample was withdrawn to determine lipoprotein (a), fibrinogen, $\mathrm{C}$ reactive protein (CRP) and D-dimer levels. Patients also answered a survey questionnaire which included family and personal history of cardiovascular disease, and personal habits. Weight, height, and abdominal perimeter were also measured.

Results: $80.47 \%$ of men and $59.36 \%$ of women presented coronary heart disease. Hypertension, diabetes and dyslipidaemia were clearly associated with CHD in women whereas in men only dyslipidaemia and diabetes showed this association. D-dimer was the only marker with significantly higher values $(p<0.032)$ in men with coronary obstruction, while in women these markers were CRP $(p<0.004), L p(a)(p<0.001)$ and fibrinogen $(p<0.045)$. In the multivariate analysis, hypertension, dyslipidaemia, smoking habit and $\mathrm{Lp}(\mathrm{a})$ showed an independently association with CHD in women, whereas in men dyslipidaemia and age were the independent risk factors for CHD.

Conclusions: Our results strongly suggest that major cardiovascular risk factors associated to CHD present gender differences. Lipoprotein (a) proved to be the only differential thrombogenic factor between men and women independently associated with coronary obstruction.
\end{abstract}

Keywords: Coronary heart disease, thrombogenic markers, gender differences.

\section{INTRODUCTION}

Cardiovascular disease (CVD) is the leading cause of mortality in Europe, with 1.9 million deaths each year, greater in women (55\%) than men (43\%) [1]. Almost half of all deaths are attributed to coronary heart disease (CHD) and one third to stroke [2].

Coronary heart disease (CHD) can occur in a different way in males and females, pathophysiological mechanisms are different and the risk-benefit balance in more commonly accepted treatments may not be the same [3-5]. Onset of CHD in women occurs at approximately a decade later than men, with a greater risk profile and worse prognosis. Despite the importance of this problem for women's health, the specific characteristics of clinical manifestations, treatment and prognosis are poorly studied, largely due to an insufficient presence of women in clinical trials.

*Address correspondence to this author at the Department Thrombosis and Haemostasis, FIDEC- Fundación Investigación y Docencia Enfermedades Cardiovasculares, C/ Gurtubay s/n48013 BILBAO, Spain;

Tel: +34 946017450; E-mail: marta_vacas@ehu.es
Although there are very few studies specifically focused to female population, the classic and most important risk factors (dyslipidemia, smoking, diabetes and high blood pressure) are similar in both sexes, but differences are established mainly in diabetes mellitus and dyslipidaemia. Diabetes mellitus is a more powerful predictor of cardiovascular risk in women than in men. Low values of cholesterol associated to high density lipoprotein (HDLc) and high triglyceride concentrations have especially negative connotations in women. Simultaneous use of contraceptives and tobacco increases risk with a powerful thrombotic effect $[6,7]$. In the last decade, advances in understanding of CHD physiopathology have led to identify several thrombogenic [lipoprotein (a), fibrinogen, D-dimer] and inflammatory (C reactive protein, CRP) risk factors with a different role in CHD development, either activating coagulation, interfering in fibrinolysis or reflecting dissemination of atherosclerotic process.

The objective of our study was to determine possible gender differences in several of this thrombogenic and inflammatory markers associated with coronary obstruction. 


\section{PATIENTS AND METHODS}

We studied 502 patients (251 males and 251 women) sent to the Basurto Hospital Haemodynamic Laboratory, for cardiac catheterisation following an acute coronary episode or to diagnose coronary artery disease. None had taken antithrombic medication in 6 hours prior to the study. In all patients, coronary arteriography was performed via the femoral artery using the Judgkins technique, catheterising the left ventricle and the three main coronary trunks. Presence of coronary artery disease $(\mathrm{CHD}+)$ was established when obstruction in one of the major vessels was greater than $50 \%$. Normal group ( $\mathrm{CHD}^{-}$) group was made up of symptomatic patients sent to the Coronary Unit to diagnose obstructive coronary disease but whose coronary angiograms turned out to be normal.

A survey questionnaire about smoking and drinking habits, as well a clinical history and treatments for high blood pressure, dyslipidaemia and diabetes was performed. Weight and height were taken to calculate Body Mass Index (BMI). Patients with dyslipidaemia were defined as patients with abnormal lipid levels in the first or previous analysis and who were under lipid lowering drugs therapy. Hypertensives were patients with high blood pressure levels on admission to hospital, or who were under hypertensive treatment regardless of current blood pressure levels. Diabetes group was defined as patients with basal glucose levels $>1.26 \mathrm{mg} / \mathrm{dl}$ or under diabetic treatment regardless of current glucose levels. The cohorts of males and females examined in this study were ethnically homogenous

On admittance, previous to coronariography, blood samples were withdrawn to determine the following parameters: Lipoprotein (a) [Lp(a)], C-reactive protein (CRP), fibrinogen and D-dimer levels. Several aliquots of the remainder of each specimen were then frozen at $-70^{\circ} \mathrm{C}$ and stored for future analyses. CRP was determined by high sensitivity assay (Tina-Quant), an immunoturbimetric latex particles test (mouse anti-CRP monoclonal antibody-coated latex particles), with measurement intervals of $0.10-20 \mathrm{mg} / \mathrm{l}$, and an interseries coefficient of variation (CV) of $5.70 \%$ $(\mathrm{x}=0.55 \mathrm{mg} / \mathrm{L}) \quad$ and $2.51 \% \quad(\mathrm{x}=12.36 \mathrm{mg} / \mathrm{L}) . \quad \mathrm{D}$-dimer (Biomerieux) sandwich immunoenzyme assay was used to determine D-dimer levels, following the ELFA (Enzyme Linked Fluorescent Assay) technique, with a measurement interval of $45-10000 \mathrm{ng} / \mathrm{ml}$, and an interseries $\mathrm{CV}$ of $5.7 \%$ $(\mathrm{x}=264 \quad \mathrm{ng} / \mathrm{ml}) \quad$ and $7.1 \% \quad(\mathrm{x}=7283 \quad \mathrm{ng} / \mathrm{ml})$. Using immunonephelometry (Instrumental Laboratories I.L.), we measured fibrinogen according to Clauss's method. Lp(a) was determined by ELISA (TintElize Lp(a), Biopool), with a measurement interval of $0-60 \mathrm{mg} / \mathrm{dl}$ and an interseries $\mathrm{CV}$ of $7.7 \%(\mathrm{x}=10 \mathrm{mg} / \mathrm{dl})$ and $2.7 \%(\mathrm{x}=40 \mathrm{mg} / \mathrm{dl})$.

The study protocol was accepted by the Clinical Trials Committee of the Basurto Hospital and explained to the patients, who freely agreed to be included in the study, signing the informed consent approved by the committee.

\section{Data Analysis}

Parametric laboratory values were expressed as means and standard deviations and non parametric as medians and interquartile (Q1-Q3) ranges. To evaluate the differences in the means of quantitative variables we used analysis of variance (ANOVA) and Bonferroni for parametric variables, and for non-parametric variables the Kruskall-Wallis test and Mann-Whitney's U test. Categorical variables were compared using the $\chi^{2}$ test. In all cases, a value of $p<0.05$ was considered significant. Statistical analysis was performed using the SPSS v 17.0 software package.

\section{RESULTS}

251 women and 250 men with an average age of $67.27(11.05)$ and $64.35(11.29)$ years respectively, were studied. 150 women (59.6\%) presented coronary artery disease $(\mathrm{CHD}+)$, while this prevalence in males was $80.9 \%$ (203 patients), difference statistically significant ( $\mathrm{p}<0.001)$.

Comparing baseline characteristics between men and women, we found statistically significant differences in age $(\mathrm{p}<0.005)$, alcohol, tobacco consumption $(\mathrm{p}<0.001)$ and prevalence of hypertension $(\mathrm{p}<0.001)$, but not with BMI, although average values obtained in both sexes were overweight (Table 1).

Table 1. Clinical and Demographic Characteristics of the Population Studied

\begin{tabular}{|c|c|c|c|}
\hline & Men $(\mathbf{N}=\mathbf{2 5 1})$ & Women $(\mathbf{N}=\mathbf{2 5 1})$ & $\mathbf{p}$ \\
\hline \hline Age & $63.94(11.26)$ & $66.68(10.58)$ & 0.005 \\
\hline BMI $\left(\mathrm{Kg} / \mathrm{m}^{2}\right)$ & $27.63(3.50)$ & $27.97(4.61)$ & 0.359 \\
\hline Alcohol $(\mathrm{g} /$ week $)$ & $201.77(219)$ & $101.38(82.81)$ & 0.001 \\
\hline Smokers & $27.3 \%$ & $12.9 \%$ & 0.001 \\
\hline Dyslipidaemia & $62.8 \%$ & $59.8 \%$ & 0.495 \\
\hline Hypertension & $50 \%$ & $72 \%$ & 0.001 \\
\hline Diabetes & $25.9 \%$ & $32.6 \%$ & 0.107 \\
\hline
\end{tabular}

BMI: Body mass index.

Table 2 shows concentrations of inflammatory and thrombogenic markers studied in both sexes. Women showed higher and statistically significant values of $\mathrm{Lp}(\mathrm{a})$ $(\mathrm{p}<0.004)$ and fibrinogen $(\mathrm{p}<0.001)$.

Table 2. Statistical Analysis of Differences in Thrombogenic and Inflammatory Markers. Total Sample

\begin{tabular}{|c|c|c|c|}
\hline & Women $(\mathbf{N}=\mathbf{2 5 1})$ & Men $(\mathbf{N}=\mathbf{2 5 1})$ & P \\
\hline \hline D-dimer $(\mathrm{ng} / \mathrm{ml})$ & $447(306-708)$ & $433(273.75-900)$ & $\mathrm{ns}$ \\
\hline CRP $(\mathrm{mg} / \mathrm{L})$ & $3.29(1.28-8.45)$ & $4.21(1.52-12.53)$ & $\mathrm{ns}$ \\
\hline Lp(a) $(\mathrm{mg} / \mathrm{dl})$ & $11.69(3.07-28.17)$ & $7.93(1.46-21.59)$ & 0.004 \\
\hline Fibrinogen $(\mathrm{mg} / \mathrm{dl})$ & $41.36(117.0)$ & $358.91(93.31)$ & 0.001 \\
\hline
\end{tabular}

Parametric variables are expressed as means (SD); p values for differences between groups were determined by t Student test; non parametric variables are expressed as medians and interquartile ranges; $p$ values were determined using Mann-Whitney U test.

Patients were distributed in two groups, depending on the presence or absence of coronary artery disease $(\mathrm{CHD}+$ and CHD-, respectively); its clinical and demographic characteristics are shown in Table 3. Women and men $\mathrm{CHD}+$ showed high and significant prevalences of dyslipidaemia and diabetes mellitus, while in women only 
Table 3. Clinical and Demographic Characteristics for Women and Men with and without Coronary Obstruction

\begin{tabular}{|c|c|c|c|c|c|c|}
\hline & \multicolumn{3}{|c|}{ Women } & \multicolumn{3}{|c|}{ Men } \\
\hline & CAD+ & CAD- & $\mathbf{p}$ & CAD+ & CAD- & $\mathbf{p}$ \\
\hline Age & $\begin{array}{c}67.27 \\
(11.05)\end{array}$ & $\begin{array}{l}65.86 \\
(9.89)\end{array}$ & $\mathrm{ns}$ & $\begin{array}{c}64.35 \\
(11.29)\end{array}$ & $\begin{array}{c}62.21 \\
(11.08)\end{array}$ & ns \\
\hline $\begin{array}{c}\mathrm{BMI} \\
\left(\mathrm{kg} / \mathrm{m}^{2}\right)\end{array}$ & $\begin{array}{l}27.96 \\
(4.59)\end{array}$ & $\begin{array}{l}27.99 \\
(4.65)\end{array}$ & ns & $\begin{array}{l}27.46 \\
(3.52)\end{array}$ & $\begin{array}{l}28.34 \\
(3.34)\end{array}$ & ns \\
\hline Alcohol (g/week) & $\begin{array}{l}109.87 \\
(87.85)\end{array}$ & $\begin{array}{c}87.22 \\
(73.85)\end{array}$ & ns & $\begin{array}{l}203.72 \\
(213.9)\end{array}$ & $\begin{array}{c}193.58 \\
(242.75)\end{array}$ & $\mathrm{ns}$ \\
\hline Smokers & $15.5 \%$ & $9 \%$ & ns & $28.8 \%$ & $21.3 \%$ & ns \\
\hline Dyslipidaemia & $69.2 \%$ & $46 \%$ & 0.001 & 65.5 & $51.1 \%$ & 0.065 \\
\hline Hypertension & $79.9 \%$ & $60.4 \%$ & 0.001 & 51.5 & $43.8 \%$ & ns \\
\hline Diabetes & $38.2 \%$ & $24.5 \%$ & 0.026 & $28.6 \%$ & $14 \%$ & 0.047 \\
\hline
\end{tabular}

CAD+: with coronary artery disease; CAD-: without coronary artery disease.

BMI: body mass index.

Quantitative variables are expressed as means (SD); $\mathrm{p}$ values for differences between groups were determined by $\mathrm{t}$ Student test. Qualitative variables are expressed as \%; $\mathrm{p}$ values for differences between groups were determined by $\mathrm{X}^{2}$ test.

arterial hypertension differed significantly between the two groups $(\mathrm{p}<0.001)$.

In relation to inflammatory and thrombogenic biomarkers, women with $\mathrm{CHD}+$ showed higher and statistically significant values of CRP $(p<0.004)$, Lp (a) (p $<0.001)$ and fibrinogen $(\mathrm{p}<0.045)$, while in males $\mathrm{D}$-dimer was the only parameter associated to CHD $(\mathrm{p}<0.032)$ (Table 4).

Multivariate analysis (Table 5) adjusted for diabetes, CRP, D-dimer and fibrinogen points out that in women high blood pressure, dyslipidaemia, tobacco and $\mathrm{Lp}(\mathrm{a})$ are independently associated with CHD whereas in men the independent factors are age and dyslipidaemia.

\section{DISCUSSION}

In Spain, coronary artery disease is the first cause of mortality in men and the second in women. Increase of cardiovascular mortality with age in women is quite superior to total mortality, notably in case of ischemic heart disease, from 8/100.000 (45-54 years) to156/100.000 (65-74 years) [8].

Table 4. Statistical Analysis of Differences in Thrombogenic and Inflammatory Markers. Women and Men with and without Coronary Obstruction

\begin{tabular}{|c|c|c|c|c|c|c|}
\hline & \multicolumn{3}{|c|}{ Women } & \multicolumn{3}{|c|}{ Men } \\
\hline & CAD+ & CAD- & $\mathbf{p}$ & CAD+ & CAD- & $\mathbf{p}$ \\
\hline D-Dimer (ng/ml) & $\begin{array}{c}472.5 \\
(334.5-808.5)\end{array}$ & $\begin{array}{c}426 \\
(267-657)\end{array}$ & ns & $\begin{array}{c}453 \\
(285.75-921.75)\end{array}$ & $\begin{array}{c}349.5 \\
(233-263)\end{array}$ & 0.032 \\
\hline CRP (mg/L) & $\begin{array}{c}4.28 \\
(1.57-11.24)\end{array}$ & $\begin{array}{c}2.52 \\
(1.17-5.6)\end{array}$ & 0.004 & $\begin{array}{c}4.16 \\
(1.52-12.53)\end{array}$ & $\begin{array}{c}4.26 \\
(1.53-12.95)\end{array}$ & ns \\
\hline $\mathrm{Lp}(\mathrm{a})(\mathrm{mg} / \mathrm{dl})$ & $\begin{array}{c}20.1 \\
(6.59-35.16)\end{array}$ & $\begin{array}{c}5.3 \\
(1.48-16.34)\end{array}$ & 0.001 & $\begin{array}{c}8.05 \\
(1.76-23.31)\end{array}$ & $\begin{array}{c}4.05 \\
(1.11-19.84)\end{array}$ & $\mathrm{ns}$ \\
\hline Fibrinogen $(\mathrm{mg} / \mathrm{dl})$ & $\begin{array}{c}425.86 \\
(123.85)\end{array}$ & $\begin{array}{c}394.86 \\
(103.95)\end{array}$ & 0.045 & $\begin{array}{l}358.96 \\
(95.02)\end{array}$ & $\begin{array}{l}358.72 \\
(86.66)\end{array}$ & ns \\
\hline
\end{tabular}

As expected, in our study the prevalence of CHD was higher in men, while the average age was higher in women confirming that women develop CHD with temporal delay respect to men.

Regarding major cardiovascular risk factors, some differences between sexes have been found: women presented higher prevalence of arterial hypertension-arterial blood pressure increases with age more powerfully than in men, so from 60 years the prevalence of hypertension is greater in women. A lower consumption of tobacco and alcohol and an increased prevalence of diabetes were also found in women. Many studies [9-11] have shown that at the onset of coronary heart disease, women have worse prognosis than men, partly due to a major accumulation of risk factors: an older age and a higher presence of hypertension and diabetes.

D-dimer is a primary degradation product of crosslinked fibrin, and elevated D-dimer levels suggest ongoing thrombin generation and breakdown. Vijay G Kalaria et al. [12] studied 791 men and 254 women with myocardial infarction and found that high levels of D-dimer were associated with an increased risk of recurrent coronary 
events in men but not in women. In our study high levels of D-dimer were significantly associated with coronary obstruction only in men.

$\mathrm{CRP}$, fibrinogen and $\mathrm{Lp}(\mathrm{a})$ values were significantly higher in women with CHD, while in men only $\mathrm{Lp}$ (a) values were high, although without statistical significance. Several authors [13,14] have demonstrated that CRP predicts cardiovascular risk in women, inflammation may act not only promoting atherogenesis but also destabilizes the vulnerable atherosclerotic plaques. Regarding fibrinogen, all studies agree that menopause markedly increases fibrinogen concentrations, which would be one of the factors that contribute to enhance cardiovascular pathology in postmenopausal women [15-17].

Table 5. Biomarkers Independently Associated to Coronary Arterial Disease (CAD+) in Men and Women. Multivariate Analysis ${ }^{*}$

\begin{tabular}{|c|c|c|c|c|}
\hline & & OR & CI & $\mathbf{p}$ \\
\hline \hline \multirow{3}{*}{ Women } & Lipoprotein (a) & 1.059 & $1.034-1.084$ & 0.000 \\
\cline { 2 - 5 } & Dyslipidemia & 2.516 & $1.355-4.673$ & 0.003 \\
\cline { 2 - 5 } & Hypertensión & 3.001 & $1.473-6.114$ & 0.002 \\
\cline { 2 - 5 } & Smokers & 2.663 & $1.021-6.946$ & 0.045 \\
\hline \multirow{2}{*}{ Men } & Dyslipidemia & 2.612 & $1.245-5.480$ & 0.011 \\
\cline { 2 - 5 } & Age & 1.041 & $1.005-1.079$ & 0.025 \\
\hline
\end{tabular}

OR: odds ratio; CI: confidence interval of $95 \%$.

*Model adjusted for diabetes, fibrinogen, d-dimer and CRP.

$\mathrm{Lp}$ (a) lipoprotein is a low-density lipoprotein particle in which apolipoproteín B-100 is linked by a single interchain disulfide bridge to a unique glycoprotein, apoprotein(a) $[18,19]$. Although the mechanism is not clearly established, elevated Lp (a) values had been considered an independent risk factor for the atherosclerosis and thrombosis pathophysiological process in CHD [20]. Jacqueline Suk Danik et al. [21] in a prospective study that assessed 27.791 healthy women in a follow-up of 10 years, found that women with Lp (a) levels $>30 \mathrm{mg} / \mathrm{dl}$ were more sensible to suffer coronary problems or stroke; if levels were $\geq 65 \mathrm{mg} / \mathrm{dl}$, the probability to develop a heart attack or an ischemic stroke or to need cardiovascular intervention (surgery or angioplasty) or even to die from cardiovascular disease, increases a $67 \%$, compared with women who had low Lp (a) levels. Women with Lp (a) concentrations exceeding $65 \mathrm{mg} / \mathrm{dl}$ and LDLc levels $\geq 120 \mathrm{mg} / \mathrm{dl}$ enhanced the risk to develop the same clinical events to $80 \%$.

Results of the multivariate analysis have confirmed that Lp (a), arterial hypertension, dyslipidaemia and cigarette smoking were the most powerful factors to predict CHD in women's group due to they were independently related to CHD. Diabetes, D-dimer and fibrinogen are associated with an increased risk of coronary heart disease in women, but this relationship lost significance in the multivariate adjustment, when other risk factors are taken into account. In males, dyslipidaemia and age were independently associated with CHD.

Our results strongly suggest that major cardiovascular risk factors associated to CHD present gender differences. Lipoprotein (a) proved to be the only differential thrombogenic factor between men and women independently associated with coronary obstruction.

\section{ACKNOWLEDGEMENTS}

This study was made possible by grants received from the Basque Government Department of Health (Ref. 2002/11009), the University of the Basque Country (Ref.9/UPV00103.103.14001/2001) and Bilbao Bizkaia Kutxa Obra Social (Ref. 67009/2007).

\section{REFERENCES}

[1] Petersen S, Peto V, Scarborough P, Rayner M. Brithios Heart Foundation Health Promotion Research Group. Coronary heart disease statistics 2005. Oxford: British Heart Foundation; 2005

[2] Bello N, Mosca 1. Epidemiology of coronary Heart disease in women.) Prog Cardiovasc Dis 2004; 46: 287-95.

[3] Patel H, Rosengern A, Ekman I. Symptoms in acute coronary syndromes: does sex make difference? Am Heart J 2004; 148: 27 33.

[4] Brieger Eagle KA, Goodman SG, Steg PG, Budaj A, White K. Acute Coronary disorders without chest pain, an underdiagnosed and undertreated high-risk group: insights from the Global Registry of Acute and Events. Chest 2004; 126: 461-9.

[5] Kudenchuk PJ Maynard C, Martin JS, Wirkus M, Weaver D, MITI Project Investigators. Comparison of presentation, treatment and outcome of acute myocardial infarction in men versus women (the Myocardial Infarction Triage and Intervention Registry). Am J Cardiol 1996; 78: 9-14.

[6] Lidón MR. Cardiovascular disease in women. Cardiovasc Risk Factors 2005; 14: 112-21.

[7] The American Diabetes Association. Clinical practice recommendations 1998. Diabetes Care 1998; 21:S23-32.

[8] Marrugat J, Elosua R, Martí H. Epidemiology of ischemic heart disease in Spain: estimation of the number of cases and trend from 1997 to 2005. Rev Esp Cardiol 2002; 55: 337-46.

[9] Marrugat J, Sala J, Aboal J. Epidemiology of cardiovascular disease in women. Rev Esp Cardiol 2006; 59: 264-74.

[10] Figueras J. Higher mortality in women undergoing primary angioplasty. Another gender enigma? Rev Esp Cardiol 2006; 59: 1096-8.

[11] Vakili B, Kaplan R, Brow D. Sex based differences in early mortality of patients undergoing primary angioplasty for acute myocardial infarction. Circulation 2001; 104: 3034-8.

[12] Vijay G, Kalaria, Wojciech Zareba, et al. Gender-related differences in thrombogenic factors predicting recurrent cardiac event in patients after acute myocardial infarction. Am J Cardiol 2000; 85: 1401-8

[13] Marroquin OC, Kip KE, Mulukutla SR, et al. Inflammation, endothelial cell activation, and coronary microvascular dysfunction in women with chest pain and no obstructive coronary artery disease. Am Heart J 2005; 150(1): 109-15

[14] Kip KE, Marroquin OC, Shaw LJ, et al. Global inflammation predicts cardiovascular risk in women: a report from the Women's Ischemia Syndrome Evaluation (WISE) study. Am Heart J 2005; 150(5): 900-6.

[15] Lee AJ, Lowe GDO, Woodward M, Tunstallpeode H. Fibrinogen in relation to personal history of prevalent hypertension, diabetes, stroke, intermittent claudication, coronary heart disease and family history: the Scottish Heart Health Study. Br Heart J 1993; 69: 33841.

[16] Folsom AR, Wu KK, Sahar E, Davis CE. Association of hemostatic variables with prevalent cardiovascular disease and asymptomatic carotid artery aterosclerosis. Arterios Thromb 1993; 13(12): 1829. 36 . 
[17] Meade TW, Haines AP, Imeson JD, Stirling Y, Thompson SG. Menopausal status and haemostatic variables. Lancet 1983; 1: 22-4.

[18] Berg K. A new serum system in man: The Lp(a) system. Acta Pathol Microbiol Scand 1963; 59: 369-82.

[19] Utermann G, Webwe W. Protein composition of Lp(a) lipoprotein from human plasma. FEBS Lett 1983; 154: 357-61.

[20] Rosengren A, Wilhelmsen L, Eriksson E, Risberg B, Wedel H. Lipoprotein (a) and coronary heart disease: a prospective case- control study in a general population sample of middle aged men. BMJ 1990; 301: 1248- 51

[21] Suk Danik J, Rifai N, Buring JE, Ridker PM. Lipoprotein (a) measured with an assay independent of apolipoprotein (a) isoform size, and risk of future cardiovascular events among initially healthy women. JAMA 2006; 296(11): 1363-8.

(C) Marta Vacas; Licensee Bentham Open.

This is an open access article licensed under the terms of the Creative Commons Attribution Non-Commercial License (http://creativecommons.org/licenses/by$\mathrm{nc} / 3.0 /$ ) which permits unrestricted, non-commercial use, distribution and reproduction in any medium, provided the work is properly cited. 